\title{
Protein Phosphatase 1-Deficient Mutant Drosophila Is Affected in Habituation and Associative Learning
}

\author{
Zoltán Asztalos, ${ }^{1}$ Jörg von Wegerer, ${ }^{2}$ Gerald Wustmann, ${ }^{3}$ Viktor Dombrádi, János Gausz, ${ }^{5}$ Hanns-Christof \\ Spatz, ${ }^{2}$ and Peter Friedrich' \\ 'Institute of Enzymology, Biological Research Center, Hungarian Academy of Sciences, Budapest, H-1518, Hungary, \\ ${ }^{2}$ Institut für Biologie III, Universität Freiburg, D-7800 Freiburg, Germany, ${ }^{3}$ Institut für Neurobiologie und Hirnforschung, \\ D-3010 Magdeburg, Germany, ${ }^{4}$ Department of Medical Chemistry, University School of Medicine, Debrecen, $\mathrm{H}-4026$, \\ Hungary, and 5 Institute of Genetics, Biological Research Center, Hungarian Academy of Sciences, Szeged, H-6701, \\ Hungary
}

The learning and memory of Drosophila melanogaster strains carrying the Su-var(3)6 mutation, which is known to affect the structural gene of a protein phosphatase 1 isoenzyme, PP1(87B), were studied in various behavioral paradigms. Three lines of Drosophila comprising the Su-var(3) $6^{01} \mathrm{mu}$ tation in different genetic backgrounds were shown to have diminished protein phosphatase 1 activity and behavioral anomalies. Associative olfactory learning and visual conditioning were impaired. Olfactory acuity for the odorants used and response to electric shock were largely unchanged in the mutant lines. The motility and flight activity of the mutants were reduced. Habituation of the landing response, a nonassociative learning process, was more pronounced in heterozygotes of the mutants than in the wild-type control strains. Taken together with earlier data, the results indicate that protein phosphatase PP1(87B), while affecting several cellular processes, is also part of the biochemical machinery of various forms of neuromodulation in Drosophila.

IKey words: Drosophila, protein phosphatase 1, phosphatase-deficient mutant, landing response, habituation, associative learning, memory]

Several lines of evidence point to the mechanistic role of CAMPdependent protein phosphorylation in the learning processes of the fruit fly Drosophila melanogaster. Mutants with abnormal cAMP metabolism have memory deficits: dunce is defective in a cAMP-specific phosphodiesterase (Byers et al., 1981; Chen et al., 1986; Davis and Davidson, 1986; Qui et al., 1991), whereas rutabaga lacks the calcium/calmodulin-activated component of adenylate cyclase (Dudai and Zvi, 1984; Livingstone et al., 1984; Levin et al., 1992). Feeding of phosphodicsterase inhibitors to wild-type flies mimics the learning/memory anomaly observed in these mutants (Folkers and Spatz, 1984; Asztalos et al., 1991).

Received Apr. 14, 1992; revised Sept. 8, 1992; accepted Sept. 10, 1992.

We thank Dr. G. Reuter (Department of Genetics, Martin Luther University, Halle, Germany) for the generous supply of some Drosophila strains used in this study and Drs. A. Aszódi, G. Tusnádi, and G. Tusnádi, Jr., for help in statistical analysis. The devoted technical assistance of Mrs. K. Majzik and Mrs. E. Lelkes is gratefully acknowledged. This work was supported by Grants OTKA (Hungary) 312 and OTKA I./3-1364 (to P.F.). OTKA 1501 (to Dr. P. Gergely), OTKA 920 (to J.G.), HCB 44/92/I (to Z.A.), DFG (Sp 172/10-1), and DFG (Wu 185).

Correspondence should be addressed to Dr. Peter Friedrich, Institute of Enzymology, Biological Research Center, Hungarian Academy of Sciences, Budapest, P.O. Box 7, H-1518, Hungary.

Copyright (c) 1993 Society for Neuroscience $0270-6474 / 93 / 130924-07 \$ 05.00 / 0$
Transgenic Drosophila expressing the heat-stable protein inhibitor of cAMP-dependent protein kinase (PKA) is impaired in learning (Drain et al., 1991). The findings that the calciumactivated neutral protease (calpain) is present in Drosophila (Pintér and Friedrich, 1988) and converts the regulatory subunit of PKA by limited proteolysis to a form showing less affinity to the catalytic subunit (Müller and Spatz, 1989) have led to a model in which the two signals of conditioning, cAMP and $\mathrm{Ca}^{2+}$, converge on PKA (Aszódi et al., 1991).

Since protein phosphorylation is a readily reversible modification, the enzymes catalyzing the removal of phosphate groups from protein $\mathrm{Ser} / \mathrm{Thr}$ side chains, the protein phosphatases, are also expected to be part of the biochemical machinery of learning. Therefore, studies were initiated on Drosophila protein phosphatases, and both the type 1 and type 2 enzymes (cf. Cohen, 1989) were detected in the flies and were shown to be very similar to their mammalian homologs (Dombrádi et al., 1987a,b; Orgad et al., 1987). It was also demonstrated that protein phosphatase 1 (PP1) was the predominant active phosphatase in most Drosophila tissues, including larval brain (Dombrádi et al., 1987a). By exploiting the high homology with mammalian counterparts, four PPl catalytic subunit genes were recognized and localized in the genome (Dombrádi et al., 1989). Mutants in one of these, gene PP1(87B), have diminished PP1 activity (Dombradi et al., 1990a), and two alleles develop a mitotic delay in the third instar larvae (Axton et al., 1990). These mutants were originally isolated as lethals in the ck19 complementation group (Gausz et al., 1981), and later it was shown that they were suppressors of position effect variegation (Reuter et al., 1987). One allele of this complementation group, $S u$-var(3)6 $6^{o I}$ (Reuter et al., 1987), which carries a mutation in the PP1(87B) gene (Dombrádi et al., 1991), may reach adult age even in the homozygous state. This rendered it possible to study the behavioral effects of PPI(87B) deficiency in adult flies. It is shown below that both habituation of the landing response and associative learning are affected in these flies.

\section{Materials and Methods}

Drosophila strains. Canton-S and Berlin were used as wild-type strains. The position effect variegation suppressor mutant $S u$-var(3) $6^{\circ \prime}$ was isolated by Reuter et al. (1987) from Canton-S carrying the inversion $\operatorname{In}(1) w^{\text {nat }}$ and was maintained in the following lines: line $51, \operatorname{In}(1) w^{\text {math }} ; \mathrm{Su}$ -

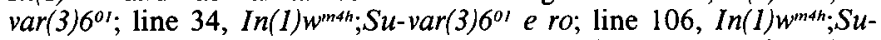
$\operatorname{var}(3) 6^{\circ 1}$ e red; line $121, \operatorname{In}(1) w^{m+h} ; \mathrm{cu} S u-\operatorname{var}(3) 6^{01}$ e ro. All four lines 
were bred as heterozygous stocks with $T M 3$ balancer chromosome. Lines 34,106 , and 121 were derived from line 51 by appropriate recombinations, to remove possible unidentified mutations from the major part of the third chromosome. Thus, line 34 was generated by recombination between line 51 and strain $\operatorname{In}(1) w^{m 4 h}$; se ss e ro, whereas in line 121 the third chromosome contained parts of chromosomes $\mathrm{cu}$ kar ry and se ss e ro, on either side of the $S u$-var(3) $\sigma^{o l}$ mutation. In line 106 , the original line 51 was recombined with a third chromosome carrying $e$ red marker mutations. Strain $\operatorname{In}(1) w^{m 4 h}$; se ss e ro was also used in this study as a "marker control." It follows from the above genotypes that all $S u$-var $(3) 6^{\circ \prime}$ homozygotes and heterozygotes have normal red eyes, since this dominant mutation suppresses variegation of the $w^{+}$gene, that is, the occasional lack of $w^{+}$expression due to adjacent heterochromatin. White-eyed flies were only found in control strains $I n(1) w^{m 4 h}$ and $I n(l) w^{m 4 h}$; se ss $e m$, in which the red or brown (se) eye pigment was reduced to about $10 \%$. The flies were grown on a standard medium of sugar, cornmeal, yeast, and agar that contained the mold inhibitor Nipagin. Breeding and experiments were carried out at $24{ }^{\circ} \mathrm{C}$ and $60 \%$ humidity. Mutant flies were selected under nitrogen anesthesia, within less than $5 \mathrm{~min}$, or cold anesthesia on the basis of morphological markers, and were kept on fresh standard cornmeal medium for at least $16 \mathrm{hr}$ before the experiment.

For the landing response experiments, only red eyed imagos with persistent flight activity can be used. This condition would not be met with homozygous mutants or heterozygotes carrying the $T M 3$ balancer, since the latter comprises the dominant Ser mutation, which affects the wings. Therefore $T M 3$ was outcrossed with wild-type Berlin, a persistent flier: the progeny not carrying TM 3 from crosses between $\operatorname{In}(1) w^{m 4 h} ; S u$ $\operatorname{var}(3) 6^{01} / T M 3$ and wild-type Berlin were selected for the experiments. We used as control the progeny from crosses between Canton-S In $(1) w^{\text {math }}$ (obtained from Dr. G. Reuter, Martin Luther University, Halle, Germany) and wild-type Berlin flies.

Olfactory associative learning was measured according to Tully and Quinn (1985) with some modifications as described earlier (Asztalos et al., 1991). The learning paradigm ran as follows. The flies were placed in the training tube, and odor-free air was sucked through at a rate of 40 liters $/ \mathrm{hr}$ for $90 \mathrm{sec}$. Then flies were shocked with $90 \mathrm{~V}$ (AC) for 1 sec every $5 \mathrm{sec} 12$ times, and during this $60 \mathrm{sec}$ period the A odorant, contained in a glass cup, was presented borne by the air stream as given above. Then the tube was flushed with odor-free air for $30 \mathrm{sec}$ (interodor rest period). The B odor was then presented for $60 \mathrm{sec}$ as above, but without electric shock, followed by another $30 \mathrm{sec}$ of rest period. The flies were tested by transferring them after another $60 \mathrm{sec}$ in the central sliding compartment to the choice point of the apparatus and were allowed to disperse in the two (A and $\mathrm{B}$ ) testing tubes, with air-borne $\mathrm{A}$ and $\mathrm{B}$ odorants, respectively, for $120 \mathrm{sec}$. The flies in the tubes were anesthetized by cooling and counted. The experiment was then repeated with fresh flies and the two odors were interchanged in respect of association with electric shock. Instead of calculating the learning index $L$ as done earlier (cf. Asztalos et al., 1991), the data were expressed in terms of a performance index, PI (Boynton and Tully, 1992). The PI also gives the fraction of flies avoiding the shock-associated odor corrected for the fraction of flies avoiding the shock-unassociated odor and averaged for the two half-experiments, but in this calculation the flies remaining in the central sliding compartment, that is, those not responding at all, are disregarded. The use of PI is warranted by the fact that $S u$-var flies have diminished motility, which results in an increase in the number of flies remaining in the central compartment. Inclusion of these flies in the calculations would have led to fallaciously low learning indices.

Odor avoidance was determined in Tully and Quinn's (1985) apparatus as described earlier (Asztalos et al., 1991) with the modification that odor intensity was adjusted not by varying the odor cup diameters, but rather by diluting the odorant with paraffin oil. The two odorants used were 4-methylcyclohexanol (MCH) and D,L-3-octanol (3-octanol), both purchased from Janssen Chimica (Beerse, Belgium). As with olfactory learning, flies remaining in the central compartment were not considered.

Electric shock avoidance was measured according to Drain et al. (1991) in Tully and Quinn's (1985) apparatus. Copper grids were inserted, as in the learning paradigm, into the tubes on either side of the choice point. During the test, one of the grids was electrified with $90 \mathrm{~V} \mathrm{AC}$. Flies were transferred to the choice point, where they distributed between the electrified and nonelectrified grids. After $2 \mathrm{~min}$ the flies were trapped in the tubes and counted. The procedure was repeated with
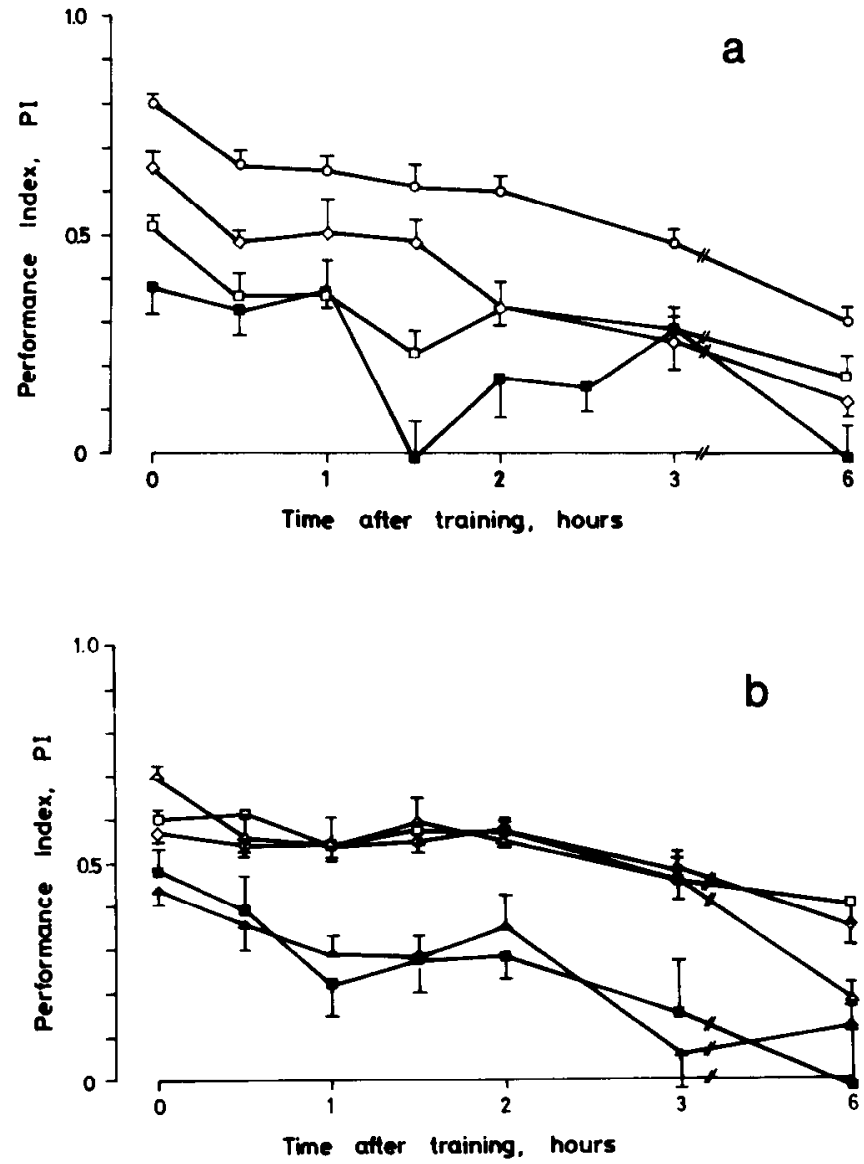

Figure l. Time course of memory decay of wild-type and mutant flies in the olfactory learning paradigm. PI is indicated as a function of time after training. The data are mean \pm SEM of 5-15 measurements. $a$ : $O$, wild-type Canton-S; $\diamond, \operatorname{In}(1) w^{m \text { th }} ; \square$, line 51 heterozygote; $\square$, line 51 homozygote. $b$ : $\diamond, \operatorname{In}(1) w^{m 4 h}$; se ss e ro, "marker control"; $\triangle$ and $\square$, heterozygotes of lines 34 and 121 , respectively; $\Delta$ and $\mathbf{n}$, homozygotes of lines 34 and 121 , respectively.

fresh flies and with the other grid electrified to exclude any side bias. After this a PI was calculated as with olfactory learning, averaged for the two half-experiments.

In all above population behavioral experiments, wild-type and control strains as well as $S u$-var heterozygotes were tested with 80-120 flies at a time, whereas $S u$-var homozygotes were tested with about 15 flies at a time, because of the reduced viability of homozygotes $(5-10 \%$ in the fly populations). Control experiments with Canton-S flies showed that the results were not influenced by this difference in the number of flies. In the shock-odor learning paradigm, the following PI values were obtained (in separate experiments, but corresponding to the Canton-S curve in Fig. 1) with 100 and 15 flies, respectively: 0 time, $0.76 \pm 0.02$ $(n=6)$ and $0.78 \pm 0.06(n=5) ; 1 \mathrm{hr}, 0.71 \pm 0.04(n=4)$ and $0.70 \pm$ $0.09(n=4) ; 3 \mathrm{hr}, 0.56 \pm 0.04(n=4)$ and $0.59 \pm 0.04(n=5)$. A twoway analysis of variance (ANOVA) yielded an insignificant effect of number $[F(1,20)=0.05, p>0.10]$. This result is in accord with Byers' (1980) measurement (see also Tully, 1984) showing that the learning index is the same whether a group of flies is tested in one run or flies are tested individually, one each in a run, and the data summated. Flies of both sexes were used.

Habituation of the landing response. The paradigm used is described in Wittekind (1987), Wittekind and Spatz (1988), and Rees and Spatz (1989). At variance with the original design landing was elicited by the progressive movement of two black vertical stripes as described by Waldvogel and Fischbach (1991). Within the binocular field of vision of the fly, the screen carries a black mask, such that the return of the black stripes to the starting position cannot be seen. The landing activity and the degree of habituation of the response depend inter alia on stripe velocity and on the contrast of the gray stripe against the background. In the experiments reported here, the stripe velocity was 180 degrees/ 


\begin{tabular}{l}
$\begin{array}{l}\text { Table 1. Specific activity of protein phosphatase } 1 \text { in } S u-v a r(3) 6^{\boldsymbol{I}} \\
\text { flics }\end{array}$ \\
$\begin{array}{ll}\text { Specific activity } \\
\text { Strain/line }\end{array}$ \\
\hline Cantong protein $(n)$
\end{tabular}

Heterozygotes carried the TM3 balancer chromosome. The means \pm SD of $n$ measurements are given

sec with respect to the fly's viewing field. The contrast was adjusted to reach appropriate response levels. In the test, the landing stimulus is repeated 125 times at 2 sec intervals.

Visual associative learning. The conditioning apparatus developed by Menne and Spatz (1977) was described in detail by Bicker and Reichert (1978). The conditioning procedure consisted of a training phase and a test. The training phase was subdivided into several 1 min training cycles, in which two lights, one of them coupled with shaking, an aversive stimulus, were presented sequentially, each for $30 \mathrm{sec}$. One population (Pop I) experienced shaking together with violet light (DAL interference filter, $\left.\lambda_{\max }=406 \mathrm{~nm}, 110 \mathrm{~mW} / \mathrm{m}^{2}\right)$ and a resting period together with green light (IL interference filter, $\lambda_{\max }=507 \mathrm{~nm}, 8 \mathrm{~mW} /$ $\mathrm{m}^{2}$ ). During the test, the two light stimuli were presented simultaneously, each in one half of the container. At the beginning of the test, the flies were tapped into one end of the container by tilting it to one side. Immediately thereafter the container was brought back into the horizontal position. The flies were given 2 min to distribute themselves between the two lights and then their distribution was photographed. Then the container was tilted to the opposite side and brought back into the horizontal position, and the distribution of the flies again was photographed after $2 \mathrm{~min}$.

A second population (Pop II) underwent an identical procedure except that these flies experienced the aversive stimulus, shaking, together with the green light and the resting period together with the violet light.

The distribution index $\left(P_{406}\right)$ is the fraction of the flies found to be in the violet illuminated half of the container in the test. The conditioning index $(\Delta)$ is defined as the difference between the distribution indices of the two sets of populations $\left[\Delta=P_{406}\right.$ (Pop II) $-P_{406}$ (Pop I)]

By comparing two sets of populations that had undergone the same conditioning procedure except for the coupling of aversive and conditioned stimuli, a direct measure of associative learning is derived, because this way pseudoconditioning effects cancel out against each other.

Measurement of protein phosphatase 1 specific activity. PP1 activity was measured in the homogenate of adult flies on the basis of radioactivity released from ${ }^{32} \mathrm{P}$-labeled phosphorylase $a$ in the absence and presence of inhibitor-2 protein (Dombrádi et al., 1990a). Protein concentration was measured according to Read and Northcote (1981).

\section{Results}

Protein phosphatase 1 levels in Su-var(3)6 $6^{\circ 1}$

Table 1 shows the specific activity values for PP1 in adult flies of Canton-S, $\operatorname{In}(1) w^{m 4 h}$ (derived from Canton-S by an inversion in the X-chromosome and used for EMS mutagenesis to produce $S u$-var(3) $\left.6^{0 I}\right)$, the "marker control" $\operatorname{In}(1) w^{m+h}$; se ss $e$ ro, and three $S u$-var $(3) 6^{\circ \prime}$ lines. It is seen that whereas there are no significant differences in PPl specific activity among strains Canton-S, $\operatorname{In}(1) w^{m 4 h}$ and the "marker control" $\operatorname{In}(1) w^{m 4 h}$; se ss e ro, the heterozygotes and homozygotes exhibit progressively and significantly diminishing values. The residual activity in the homozygotes probably stems from PP1s other than PP1(87B), which are known to exist in Drosophila (Cohen and Dombrádi, 1989; Dombrádi et al., 1990b), although the PP1(87B) carrying the $S u$-var(3) $6^{o r}$ mutation may not be completely inactive (see Discussion).

\section{Olfactory learning of Su-var(3) $6^{01}$ flies}

The memory decay curves, that is, PI versus time after training, for Canton-S, In $(1) w^{m 4 h}, \operatorname{In}(1) w^{m 4 h}$; se ss e ro, and three $S u$ $\operatorname{var}(3) 6^{0 \prime}$ lines are shown in Figure 1 . The zero time PI values ("acquisition") decrease in the order Canton-S, $\operatorname{In}(1) w^{\text {mah }}$, line 51 heterozygote, line 51 homozygote (Fig. 1a). The curve for $\operatorname{In}(1) w^{m 4 h}$ runs otherwise nearly parallel with that of Canton-S. Line 51 heterozygote and homozygote fall below $\operatorname{In}(1) w^{\text {mith }}$ only in the first 2 and $3 \mathrm{hr}$, respectively. Line 51 homozygote has a decay curve with a minimum around $1.5 \mathrm{hr}$. The two-way ANOVA of these curves yielded the following results: $\operatorname{In}(1) w^{\text {mth }}$ versus line 51 heterozygote, highly significant strain effect $[F(1,71)=$ $27.39, p<0.001]$, highly significant time effect $[F(6,71)=26.01$, $p<0.001]$, and highly significant strain $\times$ time interaction effect $[F(6,71)=4.38, p<0.001] ; \operatorname{In}(I) w^{m 4 h}$ versus line 51 homozygote, highly significant strain effect $[F(1,85)=35.88, p<0.001]$, highly significant time effect $[F(6,85)=11.34, p<0.001]$, and significant strain $\times$ time interaction effect $[F(6,85)=2.78, p<$ 0.025]. In Figure $1 b$ the heterozygotes of lines 121 and 34 can hardly be distinguished from $\operatorname{In}(1) w^{m 4 h}$; se ss e ro ("marker control," a reference strain more adequate than Canton-S), whereas their homozygotes run much lower with a slight minimum around $1 \mathrm{hr}$. The two-way ANOVA for "marker control" versus mutant strains yielded the following results: line 34 heterozygote, no significant strain effect $[F(1,82)=0.66, p>0.1]$, highly significant time effect $[F(6,82)=21.65, p<0.001]$, and a significant strain $\times$ time interaction effect $[F(6,82)=3.72, p<0.005]$; line 121 heterozygote, no significant strain effect $[F(1,73)=0.82, p$ $>0.1]$, a highly significant time effect $[F(6,73)=8.84, p<$ $0.001]$, and insignificant strain $\times$ time interaction effect $[F(6,73)$ $=0.52, p>0.1]$; line 34 homozygote, a highly significant strain effect $[F(1,90)=73.86, p<0.001]$, a highly significant time effect $[F(6,90)=9.79, p<0.001]$, and no significant strain $\times$ time interaction effect $[F(6,90)=1.51, p>0.1]$; and line 121 homozygote, a highly significant strain effect $[F(1,65)=54.73$, $p<0.001]$, a highly significant time effect $[F(6,65)=5.53, p<$ $0.001]$, and no significant strain $\times$ time interaction effect $[F(6,65)$ $=0.87, p>0.1]$. These data clearly indicate that performance in the olfactory learning test is impaired in $S u$-var $(3) 6^{0 I}$ flies. The rapid initial decrease in performance found so far with most "memory" mutants (Tully and Quinn, 1985), with the exception of latheo ${ }^{\mathrm{P1}}$ (Boynton and Tully, in press), however, cannot be seen here.

\section{Olfactory acuity, electric shock avoidance, and motility of} Su-var(3)6 $6^{01}$ flies

We tested whether the sensory modalities involved in the above learning paradigm were affected in the mutant flies. The olfactory acuity of all three $S u$-var $(3) 6^{0 r}$ lines was measured in terms of a PI of the avoidance of the two odorants used, $\mathrm{MCH}$ and 3-octanol. Only the data for line 51 are shown (Fig. 2); lines 121 and 34 gave more or less similar results. The two-way ANOVA gave the following values (the curve for each strain is compared to the appropriate curve for Canton-S). For $\mathrm{MCH}$, line 51 heterozygote, no significant strain effect $[F(1,62)=0.54$, $p>0.1]$; line 51 homozygote, no significant strain effect $[F(1,54)$ $=2.80, p>0.1$ ]; line 34 heterozygote, no significant strain effect $[F(1,54)=0.03, p>0.1]$; line 34 homozygote, a significant 


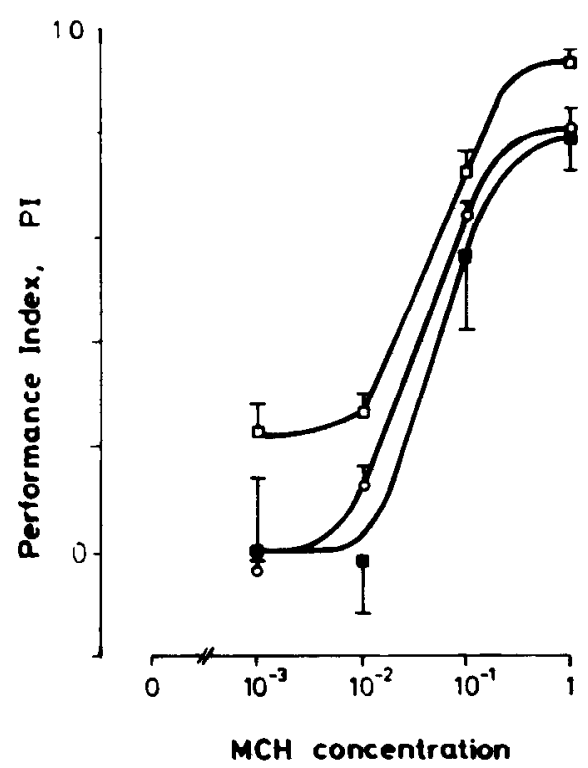

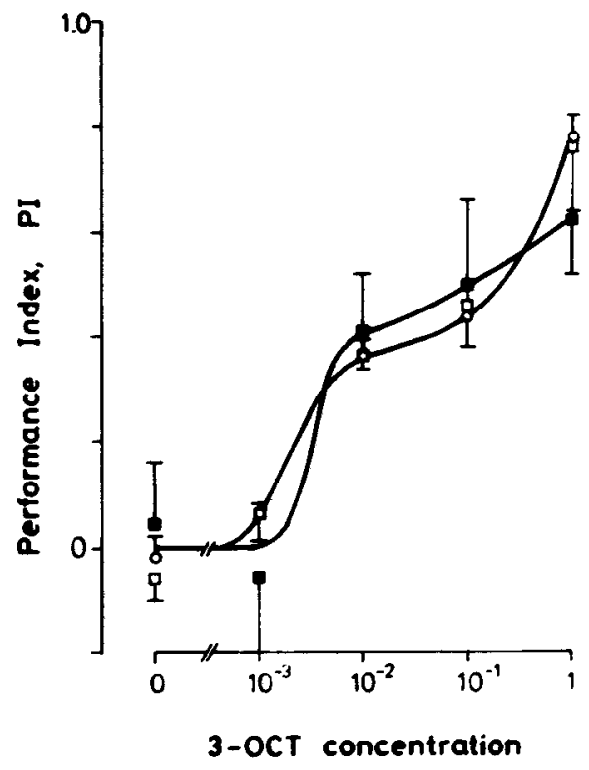

Figure 2. Odor avoidance of Canton-S and $S u$-var $(3) 6^{o I}$ line 51 heterozygous and homozygous flies. Odor concentration of 1 is undiluted odorant. The data are mean \pm SEM of 6-12 measurements. Left, $\mathrm{MCH}$ avoidance; right, 3-octanol (3-OCT) avoidance. O, wildtype Canton-S; $\square$, line 51 heterozygote; E, line 51 homozygote. strain effect $[F(1,66)=5.40, p<0.025]$; line 121 heterozygote and homozygote, no significant strain effect $[F(1,59)=0.64, p$ $>0.1$, and $F(1,69)=1.64, p>0.1$, respectively]. For 3-octanol: line 51 heterozygote and homozygote, no significant strain effect $[F(1,55)=0.29, p>0.1$, and $F(1,68)=0.59, p>0.1$, respectively]; line 34 heterozygote and homozygote, no significant strain cffect $[F(1,58)=0.07, p>0.1$, and $F(1,50)=0.34, p>$ 0.1 , respectively]; line 121 heterozygote, a highly significant strain effect $[F(1,63)=8.00, p<0.001]$; and line 121 homozygote, no significant strain effect $[F(1,72)=1.2, p>0.1]$. On the whole, the $S u$-var $(3) 6^{0 l}$ mutation affected slightly, if at all, the olfactory acuity of flies. The only significant changes were found with the $\mathrm{MCH}$ avoidance of line 34 homozygotes, where avoidance decreased by about 50\%, and with the 3-octanol avoidance of line 121 heterozygotes, where avoidance slightly increased. These differences in olfactory performance are highly unlikely to underlie the anomalies observed in olfactory learning, all the more so since before each olfactory learning experiment the 3-octanol versus $\mathrm{MCH}$ odor choice value was adjusted to 0.5 at an avoidance PI for $\mathrm{MCH}$ of about $0.7-0.8$ (except line 34 homozygote, where it was about 0.4) (see Asztalos et al., 1991). While with MCH all avoidance curves conformed to a single sigmoidal, with 3-octanol the curves were more complex with all three mutant lines, as well as with the controls. We do not know the reason of this anomaly. It may reflect two distinct receptor populations for 3-octanol or the odorant may have a general, unspecific membrane effect at high concentrations (Siddiqi, 1991).

The other stimulus in the olfactory learning paradigm is electric shock. Table 2 shows the shock avoidance of the various flies. In comparison with Canton-S, the PI values of $S u$-var lines differ insignificantly ( $p>0.05$, Student's $t$ test) with the exception of line 34 homozygote, where the PI is significantly decreased ( $p=0.034$, Student's $t$ test). This suggests that their sensing and responding to this stimulus are hardly impaired. On the other hand, the motility of $S u-\operatorname{var}(3) 6^{o 1}$ flies is diminished, which is clearly seen with the homozygotes (Table 2).

\section{Visual learning}

Only heterozygotes from crosses between $S u$-var(3) $\sigma^{o l}$ strain (line 51 and line 121) with wild-type Berlin could be tested in visual learning. In acquisition experiments (Folkers and Spatz, 1981), no significant differences of the conditioning indices were observed in comparison to the controls resulting from crosses between the $\operatorname{In}(1) w^{\text {mat }}$ background strain and wild-type Berlin (Fig. 3a). Homozygotes for the $\mathrm{Su}$-var $(3) 6^{01}$ mutation were too sluggish to be evaluated in this paradigm. In contrast, differences are seen in the memory curves (Fig. $3 b$ ). In these experiments, flies were conditioned in 12 training cycles and tested at a given time after training. Each population was tested only once. During the interval between training and test, the flies were left undisturbed in white light (Folkers and Spatz, 1981). In contrast to the control strain, after $2 \mathrm{hr}$ the conditioning index for the heterozygous $S u$-var $(3) 6^{01}$ strain is not significantly different from zero. The most striking difference, however, is found $15 \mathrm{~min}$ after training: there is a significant drop with the heterozygote followed by a slight recovery at $30 \mathrm{~min}$. The two-way ANOVA yielded a highly significant strain effect $[F(1,150)=12.48, p=$ $0.005]$, a highly significant time effect $[F(4,150)=14.12, p<$

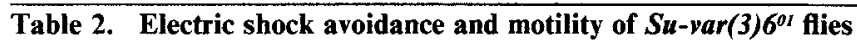

\begin{tabular}{lll} 
Strain/line & $\begin{array}{l}\text { Shock avoidance } \\
\text { PI } \times 100(n)\end{array}$ & $\begin{array}{l}\text { Motility } \\
\%(n)\end{array}$ \\
\hline Canton-S & $71 \pm 4(5)$ & $90 \pm 1(36)$ \\
In(1) $w^{\text {mah }}$ & $63 \pm 7(3)$ & $91 \pm 1(38)$ \\
$\begin{array}{l}\text { In(1) } w^{m 4 h} \text {; se ss e ro } \\
\text { Su-var(3)6 }\end{array}$ & $70 \pm 3(4)$ & $79 \pm 1(40)$ \\
$\quad$ & \\
$\quad$ Heterozygotes & & \\
$\quad$ Line 51 & $71 \pm 4(4)$ & $92 \pm 1(38)$ \\
$\quad$ Line 34 & $69 \pm 4(4)$ & $91 \pm 1(34)$ \\
$\quad$ Line 121 & $54 \pm 6(4)$ & $80 \pm 1(42)$ \\
Homozygotes & & \\
$\quad$ Line 51 & $67 \pm 12(4)$ & $88 \pm 1(38)$ \\
$\quad$ Line 34 & $44 \pm 8(4)$ & $79 \pm 2(40)$ \\
$\quad$ Line 121 & $67 \pm 15(4)$ & $69 \pm 2(43)$
\end{tabular}

Flectric shock avoidance is expressed as PI $\times 100$. Motility is expressed as the percentage of flies that left, in either direction, the central compartment in the olfactory learning test. Heterozygotes carried the $T M 3$ balancer chromosome. The means \pm SEM of $n$ measurements are given. 
Figure 3. Visual conditioning of wildtype and mutant flies. $a$, Learning. The conditioning index $\Delta$ was measured as a function of the number of training cycles. $b$, Memory. The conditioning index $\Delta$ was measured as a function of ror bars denote the SD of the mean of eight parallel experiments. The asterisks denote levels of significance $\left({ }^{* * *}, p\right.$ $<0.001 ; * *, p<0.01$ ) of the difference between Berlin $/ \operatorname{In}(1) w^{\text {mah }}(\square)$ and Ber$\operatorname{lin} / \mathrm{Su}-\operatorname{var}(3) 6^{\circ 1}(\square)$, line 51 or 121 time between training and test. The er-
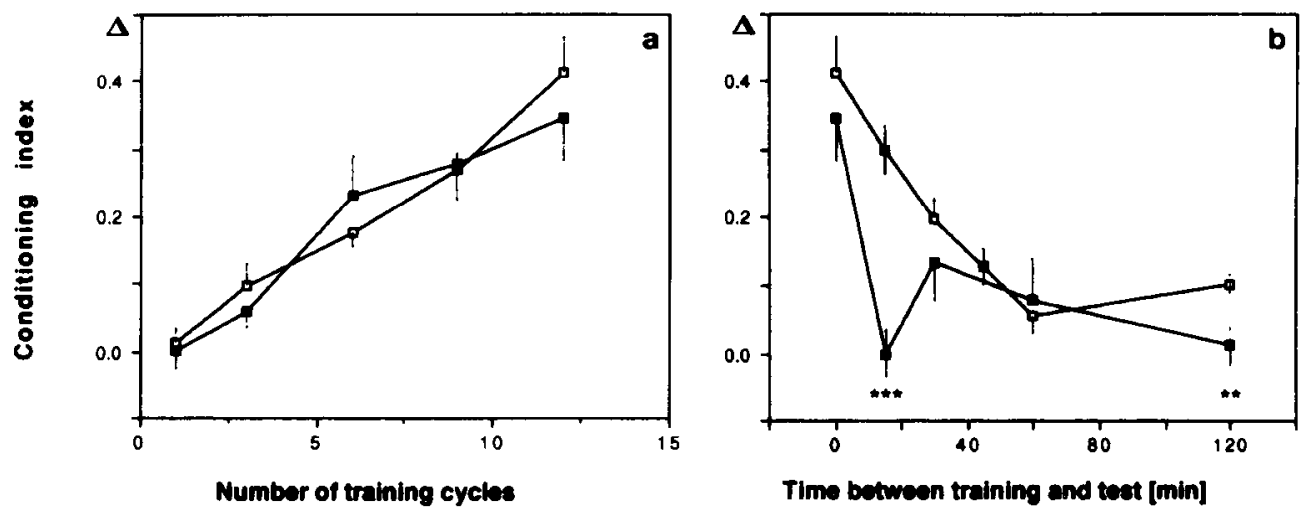

$0.0001]$, and a significant strain $\times$ time interaction effect $[F(4,150)=3.85, p=0.052]$.

\section{Habituation of the landing response}

For the habituation of the landing response, only heterozygotes produced by crosses with the persistent flier wild-type Berlin could be used (see Materials and Methods). Homozygous mutants had only poor flight activity. Figure 4 demonstrates that the heterozygotes of line 51 , line 34 , line 106, and line 121 habituate faster than the control strain or wild-type Berlin. Under the stimulus conditions used, the time between the start of the stimulus and the onset of the landing response, a parameter characteristic of this paradigm (Wittekind and Spatz, 1988; Rees

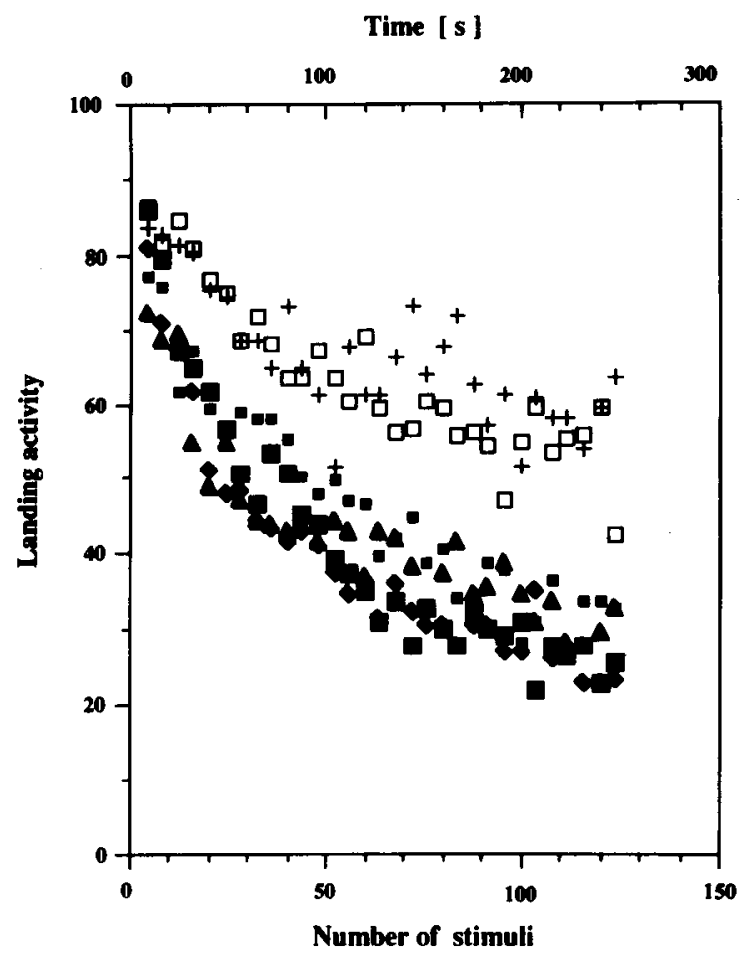

Figure 4. Habituation of the landing response in wild-type and Su$\operatorname{var}(3) 6^{\circ I}$ heterozygous flies. The landing activity is plotted as a function of the number of stimuli presented in 2 min intervals. + , wild-type Berlin $(n=21)$; $\square, \operatorname{In}(1) w^{m 4 h} /$ Berlin $(n=38)$; $\square$, line 34/Berlin $(n=44)$; $\boldsymbol{\square}$, line 51/Berlin $(n=44) ; \Delta$, line 106/Berlin $(n=52) ; \bullet$, line 121/ Berlin $(n=52)$. Approximately equal numbers of male and female flies were tested. $n=$ number of flies tested; evaluation made as described by Wittekind and Spatz (1988). and Spatz, 1989), did not differ in the heterozygous strains and the control strains. Furthermore, there was no significant change, as compared with the controls, in the time between the onset and completion of the response (data not shown; see Wittekind and Spatz, 1988).

\section{Discussion}

Drosophila melanogaster lines carrying the $S u$-var(3) $6^{01}$ mutation in different genetic backgrounds exhibit anomalies in associative and nonassociative learning paradigms. As expected from recent work (Dombrádi et al., 1991) showing that $\mathrm{Su}$ $\operatorname{var}(3) 6^{0 I}$ is a mutation in the structural gene of a PP1 enzyme, PP1(87B), all examined lines had diminished PP1 activities in a dose-dependent manner. It is assumed that the behavioral deficits are due to this enzyme deficiency. Nevertheless, it cannot be cxcluded that there is an unidentificd mutation, in addition to $S u$-var(3) $6^{\circ \prime}$ between loci $c u$ and $e$, that underlies the abnormal behaviors, since this region of the third chromosome has not been replaced in any of the lines. Narrowing this region by deficiency mapping was obviated by the fact that the relevant available deletion strains $\left[D f(3 R) e^{079}\right.$ and $\left.D f(3 R) T E 45\right]$ are lethal or give very few progeny over $S u$-var(3) $6^{o l}$, suggesting that $S u$ $\operatorname{var}(3) 6^{\circ \prime}$ is a hypomorph rather than amorph. The learning anomalies could not have originated from the ro and $e$ markers, which had been shown to affect olfactory learning (Dudai, 1977), since our "marker control," In(I) $w^{\text {mth }}$; se ss e ro, performed nearly as well as wild-type Canton-S and significantly differed from $S u$-var(3) $6^{O I}$ homozygotes.

The enzyme-deficient flies showed impaired olfactory associative learning without any major deficit in olfactory acuity and sensitivity to electric shock. The memory decay curves of homozygotcs differcd significantly from those of heterozygous and control flies: they had a low initial PI value and a local minimum around 1-1.5 hr. Such a trough has also been observed, though to a lesser extent, with both wild-type and various memory mutant flies (Spatz, 1985; Tully and Quinn, 1985), and has been interpreted by assuming different, overlapping memory phases (Tully et al., 1990; Tully, 1991).

Another feature of the olfactory learning of $S u$-var $(3) 6^{\circ}$ homozygotes is that there is no rapid initial memory decay observed with the dunce, rutabaga, and amnesiac memory mutants of Drosophila (Tully and Quinn, 1985). From our current incomplete knowledge of the biochemical reactions underlying olfactory learning in Drosophila, we may assume, by analogy with Aplysia (Braha et al., 1990) and Hermissenda (Alkon and Nelson, 1990), that short-term memory resides in the phosphorylation of some protein(s), possibly related to $\mathrm{K}^{+}$channels. 
The decay of this short-term memory should then involve dephosphorylation, as indicated in the case of Aplysia (Endo et al., 1991). We do not know, however, how the lack of PP1(87B) in Drosophila brings about the observed time course of memory decay.

In the visual learning paradigm, $S u$-var(3) $6^{o 1}$ homozygotes could not be evaluated owing to their decreased motility. Impairment in motility was also observed in olfactory learning, but it did not interfere with the measurement, because of the lesser demand for movement in the olfactory paradigm. In visual learning, the heterozygotes did not differ from the control strain in acquisition, but failed to show a conditioned response 15 min after training. This phenomenon is reminiscent of a rapid initial decrease of the conditioning index seen in many but not all of our experiments on wild-types (sce Folkers and Spatz, 1981). The phosphatase mutant may offer a chance to study whether this is an indication of an early phase of memory consolidation (Matthies, 1989).

It may look puzzling that the data on visual learning do not coincide with those on olfactory learning. It should be recalled, however, that several other differences have been observed between paradigms based on these two sensory modalities (Folkers, 1982; Folkers and Spatz, 1984). Most strikingly, the mutant mbd (mushroom body deranged) is normal in visual learning while it is severely impaired in olfactory learning (Heisenberg et al., 1985), which suggests that these two types of learning may be associated with different brain regions in the fly. Furthermore, it should be borne in mind that enzyme levels, here the significant differences in PPl activities between $S u$-var(3) $6^{\text {vI }}$ heterozygotes and homozygotes, cannot be directly correlated with behavioral parametcrs. At what degrec partial enzyme deficiency becomes critical depends on the type of learning and the paradigm used.

Habituation of the landing response was found to be faster in $S u$-var $(3) 6^{01}$ heterozygotes than in wild-type controls. Wittekind and Spatz (1988) have shown that muscle fatigue contributes little if at all to the response decrement seen during repetitive stimulus presentation. A direct indicator, recorded automatically for every response, is the time between the onset and completion of the landing reaction. This time is constant over 125 stimulus presentations. In these experiments, no difference was detected in this response time between the heterozygous $S u$-var(3) $\sigma^{0 I}$ and the control strains. It therefore seems unlikely that different degrees of muscle fatigue can explain the differences in the response decrement, even if a contribution by fatigue cannot be totally excluded.

It would bc far-fetched to envisage tentative molecular mechanisms for the opposing effects of the $S u$-var(3) $6^{0 I}$ mutation on associative learning and habituation. At our current level of understanding, even the data on habituation in Drosophila cannot be assembled in a coherent picture. The habituation of proboscis extension reflex, triggered by a gustatory stimulus, is attenuated in dunce, rutabaga and amnesiac (Duerr and Quinn, 1982). In contrast, the same mutants habituate faster in the landing response, but interference with cAMP metabolism by feeding wild-type flies phosphodiesterase inhibitors has an inverse effect: habituation is almost completely prevented (Wittekind and Spatz, 1988). Habituation of the cleaning reflex, elicited by tactile stimulation, is observed in rutabaga, but its duration is much shorter than in the wild-type (Corfas and Dudai, 1989).

The above apparently puzzling set of findings warns us that the construction of unifying molecular models for associative learning mechanisms and habituation mechanisms is premature, if ever attainable. Each sensory modality poses individual problems, and the details of central connectivity changes are unknown. An inherent difficulty in the study of these mechanisms is that they involve enzymes and other proteins, or their different isoforms, that take part in several cellular processes. Thus, the $S u$-var(3) $6^{\circ I}$ flies, apart from the learning anomalies, have decreased motility and flight activity, moderate viability, strong suppression of position effect variegation, and possibly other so far undetected phenotypic traits. This inevitable pleiotropy (see, e.g., Kulkarni et al., 1988) does not invalidate the message that the enzyme PPl $(87 \mathrm{~B})$ is involved in the biochemical machinery of associative learning and habituation in Drosophila.

\section{References}

Alkon DL, Nelson TJ (1990) Specificity of molecular changes in neurons involved in memory storage. FASEB J 4:1567-1576.

Aszódi A, Müller U, Friedrich P, Spatz H-C (1991) Signal convergence on protein kinase $A$ as a molecular correlate of learning. Proc Natl Acad Sci USA 88:5832-5836.

Asztalos Z, Lossos M, Friedrich P (1991) On the pharmacological phenocopying of memory mutations in Drosophila: alkylxanthines accelerate memory decay. Behav Genet 21:495-511.

Axton JM, Dombrádi V, Cohen PTW, Glover DM (1990) One of the protein phosphatase 1 isoenzymes in Drosophila is essential for mitosis. Cell 63:33-46.

Bicker G, Reichert H (1978) Visual learning in a photoreceptor degeneration mutant of Drosophila melanogaster. J Comp Physiol 127: 29-38.

Boynton S, Tully T (1992) latheo, a new gene involved in associative learning and memory in Drosophila melanogaster, identified from $P$ element mutagenesis. Genetics 131:655-672.

Braha O, Dale N, Hochner B, Klein M, Abrams TW, Kandel ER (1990) Second messengers involved in the two processes of presynaptic facilitation that contribute to sensitization and dishabituation in Aplysia sensory neurons. Proc Natl Acad Sci USA 87:2040-2044.

Byers D (1980) Studies on learning and cyclic AMP phosphodiesterase of the dunce mutant of Drosophila melanogaster. $\mathrm{PhD}$ thesis, California Institute of Technology.

Byers D, Davis RL, Kiger JA Jr (1981) Defect in cyclic AMP phosphodiesterase due to dunce mutation of learning in Drosophila melanogaster. Nature 289:79-81.

Chen C-N, Danomen N, Davis RL (1986) Molecular analysis of cDNA clones and the corresponding genomic coding sequences of the Drosophila dunce ${ }^{+}$gene, the structural gene for cAMP-dependent phosphodiesterase. Proc Natl Acad Sci USA 83:9313-9317.

Cohen $P$ (1989) The structure and regulation of protein phosphatases. Annu Rev Biochem 58:453-508.

Cohen PTW, Dombrádi V (1989) Three novel protein phosphatases identified by recombinant DNA techniques. Adv Protein Phosphatases 5:447-463.

Corfas G, Dudai Y (1989) Habituation and dishabituation of a cleaning reflex in normal and mutant Drosophila. J Neurosci 9:56-62.

Davis RL, Davidson N (1986) The memory gene dunce encodes a remarkable set of RNAs with internal heterogeneity. Mol Cell Biol 6:1464-1470.

Dombrádi V, Friedrich P, Bot B (1987a) Protein phosphatase type 1 and type 2 in Drosophila melanogaster. Comp Biochem Physiol [B] 87:857-861.

Dombrádi V, Gergely P, Bot G, Friedrich P (1987b) Purification of the catalytic subunit of protein phosphatase-1 from Drosophila melanogaster. Biochem Biophys Res Commun 144:1175-1181.

Dombrádi V, Axton JM, Glover DM, Cohen PTW (1989) Cloning and chromosomal localization of Drosophila cDNA encoding the catalytic subunit of protein phosphatase 1 ; high conservation between mammalian and insect sequences. Eur J Biochem 183:603-610.

Dombrádi V, Axton JM, Barker HM, Cohen PTW (1990a) Protein phosphatase 1 activity in Drosophila mutants with abnormalities in mitosis and chromosome condensation. FEBS Lett 275:39-43. 
Dombrádi V, Axton JM, Brewis ND, da Cruz e Silva EF, Alphey L Cohen PTW (1990b) Drosophila contains three genes that encode distinct isoforms of protein phosphatase 1. Eur J Biochem 194:739745.

Dombrádi V, Gausz J, Cohen PTW (1991) The structure and function of protein phosphatase 1 (87B) gene in Drosophila phosphatase mutants. Adv Protein Phosphatases [Suppl] 6:75-76.

Drain P, Folkers E, Quinn WG (1991) cAMP-dependent protein kinase and the disruption of learning in transgenic flies. Neuron 6:7182.

Dudai Y (1977) Properties of learning and memory in Drosophila melanogaster. I Comp Physiol 114:69-89.

Dudai Y, Zvi S (1984) Adenylate cyclase in the Drosophila memory mutant rutabaga displays an altered $\mathrm{Ca}^{2+}$ sensitivity. Neurosci Lett 47:119-124.

Duerr JS, Quinn WG (1982) Three Drosophila mutations that block associative learning also affect habituation and sensitization. Proc Natl Acad Sci USA 79:3646-3650.

Endo S, Ichinose M, Critz SD, Eskin A, Byrne JH, Shenolikar S (1991) Protein phosphatases and their role in control of membrane currents in Aplysia neurons. Adv Prot Phosphatases 6:411-432.

Folkers E (1982) Visual learning and memory of Drosophila melanogaster wild type C-S and the mutants dunce, amnesiac, turnip and rutabaga. J Insect Physiol 28:535-539.

Folkers E, Spatz H-C (1981) Visual learning behavior in Drosophila melanogaster wild-type AS. J Insect Physiol 27:615-622.

Folkers E, Spatz H-C (1984) Visual learning performance of Drosophila melanogaster is altered by neuropharmaca affecting phosphodiesterase activity and acetylcholine transmission. J Insect Physiol 30:957-965.

Gausz J, Gyurkovics H, Bencze G, Awad AAM, Holden JJ, Ish-Horowitz $\mathrm{D}$ (1981) Genetic characterization of the region between $86 \mathrm{~F} 1,2$ and $87 \mathrm{~B} 15$ on the chromosome 3 of Drosophila melanogaster. Genetics 98:775-789.

Heisenberg M, Borst A, Wagner S, Byers D (1985) Drosophila mushroom body mutants are deficient in olfactory learning. J Neurogenet 2:1-3.

Kulkarni SJ, Steinlauf AF, Hall JC (1988) The dissonance mutant of courtship song in Drosophila melanogaster: isolation, behavior and cytogenetics. Genetics 118:267-285.

Levin LR, Han P-L, Hwaung PM, Feinstein PG, Davis RL, Reed RR (1992) The Drosophila learning and memory gene rutabaga encodes a $\mathrm{Ca}^{3+} /$ calmodulin-responsive adenylyl cyclase. Cell 68:479-489.

Livingstone MS, Sziber PP, Quinn WG (1984) Loss of calcium/calmodulin responsiveness in adenylate cyclase of rutabaga, a Drosophila learning mutant. Cell 37:205-215.

Matthies H (1989) In search of cellular mechanisms of memory. Prog Neurobiol 32:277-349.

Menne D, Spatz H-C (1977) Color vision in Drosophila melanogaster. J Comp Physiol 114:301-312.
Müller U, Spatz H-C. (1989) $\mathrm{Ca}^{2+}$-dependent proteolytic modification of the cAMP-dependent protein kinase in Drosophila wild-type and dunce memory mutants. J Neurogenet 6:95-114.

Orgad S, Dudai Y, Cohen P (1987) The protein phosphatases of Drosophila melanogaster and their inhibitors. Eur J Biochem 164:31-38.

Pintér M, Friedrich P (1988) The calcium-dependent proteolytic system calpain-calpastatin in Drosophila melanogaster. Biochem J 253: 467-473.

Qui Y, Chen C-N, Malone T, Richter L, Beckendorf SK, Davis RL (1991) Characterization of the memory gene dunce of Drosophila melanogaster. J Mol Biol 222:553-565.

Read SM, Northcote DH (1981) Minimization of variation in response to different proteins of the Coomassie blue $\mathrm{G}$ dye-binding assay. Anal Biochem 116:53-64.

Rees CT, Spatz H-C (1989) Habituation of the landing response of Drosophila wild-type and mutants defective in olfactory learning. J Neurogenet 5:105-118.

Reuter G, Gausz J, Gyurkovics H, Friede B, Bang R, Spierer A, Hall LMC, Spierer P (1987) Modifiers of position-effect variegation in the region from $86 \mathrm{C}$ to $88 \mathrm{~B}$ of the Drosophila melanogaster third chromosome. Mol Gen Genet 210:429-436.

Siddiqi O (1991) Olfaction in Drosophila. In: Chemical senses, Vol 3 , Genetics of perception and communications (Wysocky CJ, Kare MR, eds), pp 79-95. New York: Dekker.

Spatz H-C (1985) Visuelles Lernen bei Drosophila. Wege zu einer Molekularbiologie des Lernens? Funkt Biol Med 5:276-287.

Tully T (1984) Drosophila learning: behavior and biochemistry. Behav Genet 14:527-557.

Tully T (1991) Drosophila's role in identifying the building blocks of associative learning and memory. In: Perspectives in cognitive neuroscience (Lister RG, Weingartner $\mathrm{HJ}$, eds), pp 46-64. New York: Oxford UP.

Tully T, Quinn WG (1985) Classical conditioning and retention in normal and mutant Drosophila melanogaster. J Comp Physiol [A] 157:263-277.

Tully T, Boynton S, Brandes C, Dura JM, Mihalek R, Preat T, Villella A (1990) Genetic dissection of memory formation in Drosophila melanogaster. Cold Spring Harbor Symp Quant Biol 55:203-211.

Waldvogel F-M, Fischbach K-F (1991) Plasticity of the landing response of Drosophila melanogaster. J Comp Physiol [A] 169:323330.

Wittekind WC (1987) Analyse des stereotypen und insbesondere plastischen Landeverhaltens von Drosophila melanogaster. $\mathrm{PhD}$ thesis, Universität Freiburg.

Wittekind WC, Spatz H-C (1988) Habituation of the landing response of Drosophila. NATO ASI (Adv Sci Inst) Ser H [Appl Sci] 19:351368 . 